\title{
Los pueblos viriles y el yugo del caballero español. La virilidad como problema nacional en el regeneracionismo español (1890s-1910s) ${ }^{1}$
}

\author{
Darina Martykánová
}

Recibido: 23 de octubre de 2016 / Aceptado: 16 de mayo de 2017

Resumen. En la última década del siglo XIX, las élites españolas articularon un discurso de crisis y cambio que se conoce como el regeneracionismo. Postulaba la necesidad vital de transformar radicalmente la política y la sociedad española. El objetivo de los cambios propuestos era triunfar en la competencia internacional y el camino consistía, a grandes rasgos, en interiorizar las bondades de la "civilización moderna" fusionándolas con lo que se consideraban las virtudes tradicionales del carácter español, dejando de lado los rasgos negativos de ambos. En este sentido, el regeneracionismo se inscribía en un discurso transnacional de progreso y decadencia, fomentado por la expansión del nacionalismo y por la pugna por definir y encarnar los criterios de la civilización moderna. En este texto argumento que el discurso regeneracionista español planteó el problema nacional como un problema de virilidad y buscó soluciones a este mal en la recuperación de la hombría a través de la regeneración moral.

Palabras clave: masculinidad; nacionalismo; regeneracionismo; España; transnacional.

\section{[en] Virile Peoples and the Spanish Gentleman's Burden: Virility as a National Issue in the Spanish "regeneracionismo" (1890s-1910s)}

\begin{abstract}
During the last decade of the nineteenth century, Spanish elites articulated a discourse of crisis and change known as "regeneracionismo". It argued that it was essential to radically transform Spanish politics and society. The aim was to succeed in international competition and the way to do so consisted in interiorizing the virtues of "modern civilization," and merge them with what were considered as traditional strengths of Spanish character, while leaving aside the vices of the two. In this sense, the "regeneracionsimo" was part of a transnational discourse of progress and decadence, fueled by the spread of nationalism and by the struggle to define and embody the criteria of modern civilization. In this text I argue that Spanish regenerationist discourse identified the "national question" as a question of virility and sought the solutions to this evil in the recovery of virility by means of moral regeneration.

Keywords: masculinity; nationalism; regeneracionismo, Spain, transnational.
\end{abstract}

1 Este artículo se inscribe en el Career Integration Grant TECHDEM - Technocracy and Democracy: convergence, conflicts and negotiations. A comparative and global analysis of expert knowledge and political power (18-21st century), financiado por la Comisión europea dentro de la Acción Marie Curie (FP7-PEOPLE2013-CIG). Quisiera agradecer a los asistentes del taller Masculinidad, Nación y civilización en España (18301930), organizado en el marco del mismo proyecto el 15 de enero de 2016 en Madrid, por sus comentarios. Agradecimientos también para Jesús de Felipe, Hugo García, Florencia Peyrou y otros asistentes a la sesión de noviembre 2016 del Seminario de Historia Social y Cultural (UAM) en el que se debatió uno de los borradores del texto, como también a Miguel Martorell por sus comentarios esclarecedores, y a Nerea Aresti, Juan PanMontojo, Alejandro Camino y Javier Martínez Dos Santos que han leído varias versiones.

2 Universidad Autónoma de Madrid (España)

E-mail: darina.martykanova@uam.es 
Sumario. Introducción. 1. El regeneracionismo español en el contexto global. 2. La virilidad en el centro del discurso regeneracionista español. 3. El regeneracionismoy la masculinidad hegemónica de la época. 4. Conclusiones.

Cómo citar: Martykánová, D. (2017). "Los pueblos viriles y el yugo del caballero español. La virilidad como problema nacional en el regeneracionismo español (1890s-1910s)". Cuadernos de Historia Contemporánea, 39, 19-37.

\section{Introducción}

En la última década del siglo XIX, las élites españolas articularon un discurso de crisis y cambio que se conoce como el regeneracionismo. Postulaba la necesidad vital de transformar radicalmente la política y la sociedad española. Más allá de las reformas institucionales, se trataba hasta de expurgar algunas características consideradas como particulares de la llamada "raza española". El objetivo de los cambios propuestos era triunfar en la competencia internacional y el camino consistía, a grandes rasgos, en interiorizar las bondades de la "civilización moderna" fusionándolas con lo que se consideraban las virtudes tradicionales del carácter español, dejando de lado los rasgos negativos de ambos ${ }^{3}$. El regeneracionismo recibió un impulso importante con la pérdida de las colonias en 1898, pero, como muestran los expertos en el tema, en el momento del "Desastre" el discurso estaba ya bien articulado 4 . Alfonso Ortí sitúa los comienzos de esta "ambigua fenomenología ideológica del descontento político de las clases medias españolas con el Estado de la Restauración" en el momento de la "culminación de la democratización formal del Régimen de la Restauración (Ley de Asociaciones de 1887, reintroducción del sufragio universal masculino de 1890...)"5.

El género desempeñó un papel importante en la configuración de este "descontento hipercrítico" y actuó a varios niveles ${ }^{6}$. Los análisis críticos con la situación y las recetas propuestas para su remedio ponían en marcha un imaginario amplio cargado de nociones de género que naturalizaba y legitimaba ciertas observaciones y soluciones frente a otras. Es más, la identificación misma de los "males de la patria" (Lucas Mallada) estaba cargada de este tipo de nociones. Al buscar desesperadamente el diagnóstico de los problemas de la nación y los remedios para estos males, el regeneracionismo español se inscribió en un entramado discursivo complejo en el que las dicotomías conceptuales como la civilización y la barbarie, la modernidad y la tradición, hasta "lo nuestro" y "lo extranjero", adquirieron sentido a través de su asociación implícita o explícita con las nociones de género. No se trataba simple-

3 Existe una abundante bibliografía sobre el regeneracionismo español y sobre cada uno de sus protagonistas más conocidos, de calidad muy variada. Citemos varias obras colectivas que incluyen textos relevantes: Juliá, Santos (coord.): Debates en torno al 98. Estado, sociedad y politica, Madrid, 1998. Pan-Montojo, Juan (ed.): Más se perdió en Cuba. España, 1898 y la crisis de fin de siglo, Madrid, Alianza, 1998; Suárez Cortina, Manuel (ed.): La cultura española en la Restauración, Santander, Sociedad Menéndez Pelayo, 1999. González, José Antonio y Robles Egea, Antonio (ed.): Intelectuales y ciencias sociales en la crisis de fin de siglo, Barcelona, Anthropos, 2000 .

4 Juan Pan-Montojo y otros en: Pan-Montojo, Juan (ed.): Más se perdió en Cuba..., o, por ejemplo, Fusi, Juan Pablo, y Niño, Antonio (eds.): Antes del Desastre. Orígenes y antecedentes de la crisis del 98, Madrid, Universidad Complutense, pp. 99-110.

5 Ortí, Alfonso, "Regeneracionismo", en En torno a Costa. Populismo agrario y regeneración democrática en la crisis del liberalismo español, Madrid, MAPA, 1996, p. 85 (publicado por primera vez en 1988 en Reyes, Román (ed.): Terminología científico-social. Aproximación crítica, Barcelona, Anthropos, 1988, pp. 846-851). 
mente de adoptar la civilización moderna y repudiar la tradición, sino establecer la justa medida y la combinación precisa entre lo "moderno" y "lo tradicional", entre "lo nuestro" y "lo extranjero", participar en lo "universal" sin perder o diluir lo "nacional"; algo sumamente difícil teniendo en cuenta que, de por sí, estos conceptos se caracterizaron por un alto grado de ambigüedad y sus contenidos estaban siendo redefinidos y contestados en la época finisecular. De la misma forma, no debemos suponer que la construcción de ciertos elementos y características como "masculinos" y otros como "femeninos" se trasladara automáticamente en el ensalzamiento de los primeros y la estigmatización de los segundos ${ }^{7}$.

Para analizar este juego complejo me sirvo de las categorías analíticas como la "masculinidad hegemónica" y las "masculinidades subalternas" de R.W. Connell, y también la "hipomasculinidad" y la "hipermasculinidad" de Michael Kimmel, todas ellas desarrolladas sobre todo desde la sociología ${ }^{8}$. La masculinidad hegemónica se entiende como un ideal cultural que promueve "la producción de masculinidades ejemplares," incitando a los individuos a "honrar, desear y sostener el modelo hegemónico" y a "adoptar una posición de complicidad en relación con él", mientras que las masculinidades subalternas, dotadas de menor prestigio y legitimidad, coexisten con la masculinidad hegemónica en posición de subordinación simbólica ${ }^{9}$. La hipomasculinidad y la hipermasculinidad son categorías analíticas que operan con la noción de la "justa medida", es decir, llaman la atención de que la masculinidad hegemónica se define no solamente frente a una insuficiencia de virilidad que lleva al afeminamiento, sino también frente a la exageración indeseable de algunos atributos claramente identificados como viriles o la falta de autocontrol sobre ellos ${ }^{10}$.

En este artículo me centraré en cómo muchos de los regeneracionistas españoles definieron "el problema nacional" (Ricardo Macías Picavea) como un problema de virilidad. Daré cierta prioridad a los regeneracionistas que, en términos intelectuales, podrían considerarse de segunda fila, frente a los pensadores de mayor transcendencia y complejidad como podían ser Ángel Ganivet o Miguel de Unamuno ${ }^{11}$. El

7 Sobre estas dinámicas en otros contextos: Mosse, George: The Image of Man: The creation of Modern Masculinity, Oxford, Oxford University Press, 1996; Nagel, Joane: "Masculinity and Nationalism: Gender and Sexuality in the Making of Nations", Ethnic and Racial Studies, 21.2 (1998), pp. 242-269.

8 Sobre la "masculinidad hegemónica" y "masculinidades subalternas": Connell, Robert W.: "La organización social de masculinidad", en Teresa Valdés y José Olavarría (eds.): Masculinidad/es: poder y crisis, Isis Internacional, Santiago de Chile, 1994, pp. 31-48. Una crítica de la "masculinidad hegemónica", tal como la plantea Connell, en Demetriou, Demetrakis, "Connell's Concept of Hegemonic Masculinity: A Critique", Theory and Society, 30,3 , 2001, pp. 337-361. La hipomasculinidad y la hipermasculinidad en Kimmel, Michael: "Masculinidades globales: restauración y resistencia", Masculinidades globales: restauración y resistencia, en Carolina Sánchez-Palencia y J. C. Hidalgo (eds.): Masculino Plural: Construcciones de la masculinidad, Universitat de Lleida, Lleida, 2001, pp. 47-75.

9 Connell, R. W.: Masculinities, Allen \& Unwin, Sydney, 1995, pp. 79-80. En mi opinión, siendo útiles estas categorías precisamente por mostrar la pluralidad de las masculinidades y las jerarquías entre ellas, hace falta plantearse la necesidad de una categoría que abarcase no solamente lo deseable y lo respetable frente a lo estigmatizado, sometido y rechazado, sino también lo esperado, lo comprensible, lo imaginable y lo explicable en un contexto histórico dado, y que en este sentido permita identificar y analizar en su pluralidad el imaginario y las expectativas asociadas a lo masculino en este contexto, sin dejar de interrogarse sobre las dinámicas de poder entre las distintas masculinidades.

10 Es cierto que estas categorías son fruto de un contexto histórico específico y su capacidad analítica varía dependiendo de si se aplican a un modelo de relaciones de género jerárquico (que construye a la mujer como un hombre insuficiente/pasivo) o a un modelo basado en la oposición y la complementariedad, aunque siempre jerárquica, de sexos.

11 Para el pensamiento polifacético y complejo de Miguel de Unamuno, véase Díaz Freire, José Javier: "Miguel de Unamuno: la feminización de la masculinidad moderna," ponencia en el taller Masculinidad, Nación y 
propósito de esta elección es el de intentar identificar el imaginario compartido en un movimiento político-intelectual decididamente plural. La segunda contribución de mi mirada consiste en insertar el regeneracionismo español en un marco transnacional, ya que la preocupación por la degeneración nacional caracterizó los debates finiseculares en muchos lugares del planeta, sin estar siempre relacionada con los éxitos o fracasos militares de cada país.

\section{El regeneracionismo español en el contexto global}

El regeneracionismo tiende a interpretarse en el marco nacional español, y se le vincula con el ambiente de la Restauración y con el Desastre de 1898. Sin que estas interpretaciones dejen de ser válidas, al introducir una perspectiva comparada podemos observar que se inscribe claramente dentro de unas tendencias discursivas transnacionales. La visión del mundo como un escenario de la lucha feroz entre países o naciones por su supervivencia y por maximizar el poder fue hegemónica durante el fin del siglo, igual que la obsesión de las élites por la decadencia y la búsqueda frenética de soluciones. En el Imperio Otomano, esa "Turquía” que según los regeneracionistas españoles no tenía remedio, los intelectuales y políticos del cambio de siglo articularon un discurso del desastre cuyo alarmismo fue en aumento durante y después de las Guerras Balcánicas, alcanzando la cumbre a postrimeras de la Gran Guerra. Así por ejemplo los defensores otomanos de una codificación racionalista de la ley islámica (la sharía), basada en las experiencias y en los principios revelados por las ciencias modernas, creían que vivían en tiempos de "la degradación del elemento musulmán" cuando "tenía lugar una lucha feroz por la supervivencia"12. La falta del sentimiento patriótico fue habitualmente identificada como uno de los problemas principales. "Las revoluciones y las guerras son percibidas como la voluntad de Dios, sin pensar sobre sus causas", se quejaba en 1913 el intelectual otomano Tüccarzade Ibrahim Hilmi, criticando que muchos de sus compatriotas "no se identifican ni con la nación, les da igual lo que sucede." ${ }^{13}$ De hecho, el libro donde este autor exponía sus soluciones, tenía un título parecido a los tropos del regeneracionismo español: Europeizarnos, o las razones de nuestras desdichas. El parecido con el imaginario regeneracionista llama la atención: observamos un esfuerzo por casar el orden y la estabilidad con la necesidad de hacer grandes cambios imprescindibles para salvar la nación. Las glorias pasadas servían para reclamar una posición geopolítica destacada, cuando al mismo tiempo se consideraba imprescindible una redefinición de los rasgos considerados como tradicionales y su fusión con las virtudes de la civilización moderna, sin que se adoptaran sus vicios ${ }^{14}$.

civilización en España (1830-1930), organizado en el marco del proyecto Marie Curie CIG TECHDEM el 15 de enero de 2016 en Madrid.

12 Hukuk-i Aile Kararnamesi, "Münâkehât ve Mufârakât Kararnamesi Esbâb-1 Mucibe Lâyıhası (1917), reproducida en Sosyo-kültürel değişme sürecinde Türk ailesi III, Ankara, T.C.Başbakanlık Aile Araştırma Kurumu, Ankara, 1992, pp. 1141-1142.

13 Tüccarzade İbrahim Hilmi: Avrupalılaşmak, Felaketlerimizin Esbabı (Aile Hayatımızda Avrupalılaşmanın Tesiri), reproducido en Sosyo-kültürel değişme sürecinde Türk ailesi III, Ankara, T.C.Başbakanlık Aile Araştırma Kurumu, 1992. pp. 1073-1079. (primera edición en 1913).

14 Parla, Jale: Babalar ve oğullar : Tanzimat romanının epistemolojik temelleri, İletişim Yayınları, Estambul, 1993; Malecková, Jitka: Úrodná půda. Žena ve službách národa, ISV, Praga, 2002; Martykánová, Darina: "Láska, disciplína a budoucnost. Diskurz osmanských intelektuálů o dětech v rodině (1870-1918)", en Historický 
Con frecuencia se ha asumido que este discurso se limitaba a los países excluidos del club de las potencias de primer orden. Hasta analistas brillantes como Alfonso Ortí entienden la intensificación del pesimismo regeneracionista como característica de los países semiperiféricos o de capitalismo dependiente ${ }^{15}$. Sin embargo, la preocupación aguda por la decadencia estaba extendida entre los miembros de aquel club de los países europeos "centrales". La visión del progreso como un proceso constante e imparable, combinada con la jerarquización inestable de los países según criterios de civilización cambiantes, fomentaba la preocupación constante de las élites por la posición geopolítica de sus naciones. En Francia, que vivía con preocupación la ascendencia y expansión de Alemania, a la vez que competía con el Reino Unido por colonias por todo el planeta, se hicieron populares trabajos como el de Edmond Demolins cuyo título se preguntaba À quoi tient la supériorité des Anglo-Saxons?. Esta obra fue muy popular, por cierto, también en España, en el Imperio otomano, y, por razones obvias, entre las élites locales en el Egipto colonizado donde se publicó su traducción árabe sólo dos años después de su primera edición francesa ${ }^{16}$. Los "anglosajones" tampoco estaban tranquilos: los ingleses, en concreto, se preocuparon por estar perdiendo la ventaja acumulada durante la Revolución industrial y buscaron modelos en el extranjero para reformar de forma radical sus instituciones de enseñanza, incluida la enseñanza técnica y científica. Además, las élites británicas desarrollaron un discurso apocalíptico de la degeneración nacional culpabilizando de ella sobre todo a la degradación moral de las clases trabajadoras ${ }^{17}$. Incluso en la ascendente Alemania y en los triunfantes y siempre tan optimistas Estados Unidos, la obsesión por el peligro de la decadencia se agudizó alrededor del cambio de siglo, dando lugar a obras que buscaban signos de decadencia patria, no quedándose los autores contentos hasta encontrarlos ${ }^{18}$. Un imperio en plena expansión como el alemán, utilizado como ejemplo de éxito en España y en el Imperio Otomano, y temido como un rival cada vez más peligroso en Francia y en Gran Bretaña, acabó dando al mundo la elaboración más compleja de estas preocupaciones, en obras como $L a$ decadencia de Occidente (Der Untergang des Abendlandes, 1918-1923) de Oswald Spengler, si bien es cierto que esta última fue publicada después de la derrota catastrófica del país en la Gran Guerra ${ }^{19}$. El catastrofismo de este tipo de discursos no debería entenderse como un signo de fatalismo ni, por ende, como una prueba de la decadencia. La retórica de la decadencia apelaba a la recuperación individual y co-

časopis, 2008, 56/2, 249-266 y “La pareja: el nuevo ideal de matrimonio en el Imperio Otomano”, Awraq 5, pp. 75-107.

15 Ortí, "Regeneracionismo", pp. 86 y 90-91.

16 Demolins, Edmond: À quoi tient la supériorité des Anglo-Saxons?, Paris, Libraire de Paris, 1897. Swart, Koenraad W.: The Sense of Decadence in Nineteenth-Century France, Martinus Nijhoff, La Haya, 1964. La traducción al árabe es publicada en Cairo por Ahmad Fathi Zaghlul sólo dos años después de la primera edición del original. Ahmad Fathi Zaghlul, Sirr taqaddum al-inkliz al-saksuniyyin, Matba'at al-Ma'arif, Cairo, 1899, en Mitchell, Timothy, Colonising Egypt, University of California Press, Berkeley/Los Ángeles/Londres, 1991, p. 198.

17 Young, Robert M.: Darwin's Metaphor: Nature's Place in Victorian Culture, Cambridge University Press, Cambridge, 1986, capítulo 5. Greenslade, William: The concept of degeneration, 1880-1910, with particular reference to the work of Thomas Hardy, George Gissing and H. G. Wells, tesis doctoral, Universidad de Warwick, 1982..

18 Pick, Daniel: Faces of Degeneration. A European Disorder, c. 1848 - c. 1918, Cambridge, Cambridge University Press, 1996.

19 Spengler, Oswald: La decadencia de Occidente, S.L.U., Espasa, 2011. La obra se publicó por primera vez entre 1918 y 1923, pero se supone que el autor concibió la idea ya en 1911. Véase también Herman, Arthur: The idea of Decline in Western History, The Free Press, Nueva York, 1997. 
lectiva de la virilidad perdida o amenazada, con una agresividad cuya eficacia puede observarse en la movilización fervorosa hacia los proyectos coloniales, en el militarismo y belicismo, en la inversión en armamento y en la renovada pasión conquistadora y exterminadora, que caracterizó el mundo de las primeras dos décadas del siglo XX. En muchos países, por ejemplo en las repúblicas de Latinoamérica, el debate, el diagnóstico y las soluciones propuestas solían ostentar fuertes tintes raciales. No se trataba tampoco de un fenómeno exclusivamente "occidental", al observarse en Rusia, el Imperio Otomano, Japón y otros lugares ${ }^{20}$. Tampoco se puede entender esta dimensión global en términos de difusión, sino más bien como producto de un diálogo mundial conflictivo y creativo constante, ${ }^{21}$ facilitado por la circulación de conocimientos y prácticas, pero también por una observación angustiosa, alimentada por el miedo de perder el dominio y/o de ser dominados.

\section{La virilidad en el centro del discurso regeneracionista español}

Reconocer las dimensiones transnacionales del discurso de la decadencia y de la regeneración no significa dar por supuesto que éste se insertara de la misma manera en culturas políticas radicalmente distintas. En este trabajo planteo la hipótesis de que en el regeneracionismo español, la cuestión de la virilidad se planteó con especial fuerza precisamente por ser éste un discurso moralizante que cargaba sobre el individuo varón la responsabilidad de su regeneración moral ${ }^{22}$. Ante todo, se trataba de volver a ser hombres, a nivel individual, para hacerlo a nivel colectivo. Este deber yacía con peso especial en los hombros de los varones de las élites, los que se reconocían mutuamente como caballeros, por lo que he optado aquí por denominarle el yugo del caballero español.

El regeneracionismo español planteó la crítica al status quo como un problema nacional, con fuertes tintes elitistas. Sin duda fue así en el sentido de conllevar la identificación de los autores con la razón de estado: una parte importante de los regeneracionistas estaba ante todo preocupada por el debilitamiento de la posición internacional de España, a diferencia, por ejemplo, de establecer como el último fin de toda acción política el bienestar de los españoles. Estos patriotas percibían el mundo como un espacio en el que tenía lugar una competencia feroz entre las naciones. Según ellos, había naciones de primera categoría que tenían en sus manos las riendas de la humanidad. España estaba destinada a permanecer entre estas naciones "por

20 White, Frederick H.: Degeneration, Decadence and Disease in the Russian fin de siècle, Manchester, Manchester University Press, 2014. En el contexto otomano y turco resultan interesantes por su complejidad las obras de Ziya Gökalp. Wendt, Simon y Domínguez Andersen, Pablo: Masculinities and the Nation in the Modern World: Between Hegemony and Marginalization, Palgrave Macmillan, 2015. Conrad, Sebastian: The Quest for the Lost Nation: Writing History in Germany and Japan in the American Century, Berkeley, University of California Press, 2010.

21 Appadurai, Arjun: Modernity at large: cultural dimensions of globalization, Minneapolis, 1996, y The future as a cultural fact, Londres, 2013.

22 Nerea Aresti ha identificado la importancia clave de la masculinidad en el discurso sobre la crisis del 98 en Aresti, Nerea: "A la nación por la masculinidad. Una mirada de género a la crisis del 98", en Nash, Mary (ed.): Feminidades y masculinidades: arquetipos y prácticas de género, Alianza, Madrid, 2014, pp. 47-74. Richard Cleminson y Francisco Vázquez García mantienen que específicamente la crisis del 98 se planteó en términos de la virilidad nacional en declive, una afirmación que mi investigación parece confirmar. Cleminson, Richard y Vázquez García, Francisco: Los invisibles. Una historia de la homosexualidad masculina en España, 18501939, Comares Historia, Granada, 2011, pp. 194-197. 
geografía" (Macías Picavea afirmó que "nuestra preeminencia geográfica presta a España una grandeza irresistible" ${ }^{23}$ ) o "por derecho" 24 , y cualquier otro lugar en esta jerarquía se consideraba como una humillación. Mientras algunos se mostraban partidarios del colonialismo sin complejos, percibiéndolo como un rasgo definitorio de las naciones de primera, otros entendían que todos los pueblos tenían derechos y libertades, por mucho que éstos fueran usurpados, y entendían el papel de las grandes potencias como el de una familia de hermanos que deberían respetarse mutuamente y ejercer de tutores que guían con benevolencia a los "pueblos débiles" por este camino $^{25}$. Como han mostrado los trabajos de Ferran Archilés o Gemma Torres Delgado, la movilización de las nociones de género para articular este Weltanschauung -y un proyecto de conquista y dominio- era omnipresente y, con frecuencia, explícita ${ }^{26}$. Para ser una nación "potencia de primer orden", el pueblo tenía que ser un "pueblo viril." ${ }^{27}$ Las características de los pueblos viriles estaban abiertas al debate y se admitía cierta pluralidad en las maneras de serlo: así por ejemplo, la "raza anglosajona" podía serlo a su manera, algo distinta de la virilidad del pueblo español. El espíritu práctico podría reforzar la virilidad de un pueblo o raza, mientras que el idealismo, el valor y la hidalguía podrían ser fuente de virilidad para otro. En cualquier caso, el imperativo de la virilidad implicaba la independencia en términos político-militares, la fuerza económica y, en general, la capacidad de dominarse a sí mismo y, más o menos explícitamente según el autor y el asunto tratado, también la voluntad y capacidad de dominar a otros.

La categorización de las naciones tenía una dimensión histórica, basada en las glorias pasadas, atribuidas a las "demostraciones...viriles" del "sentimiento patrio" 28 . A los patriotas españoles les interesaba resaltar la importancia de las hazañas de los antepasados y fomentar la identificación absoluta con ellos (los españoles descubrimos, conquistamos, evangelizamos... etcétera), alegando que al ser españoles compartían con estos hombres del pasado "sus energías, su vitalidad, el valor y la hidalguía"29. El pasado glorioso era una prueba del "derecho" y de la capacidad de recuperarse y volver a situarse en una posición aventajada. Algunos autores proponían una visión radicalmente optimista, planteando que la recuperación rápida era la norma y que los países que según ellos no lograron "recobrar las fuerzas y el prestigio perdido" eran "excepción de la regla":

Si los males ajenos pudieran consolarnos, bastaría una rápida mirada por todos los pueblos del mundo para convencernos que todos ellos han sufrido tan terribles catástrofes como la que hoy aflige a España; y, sin embargo, exceptuando la infeliz Polonia, que algún día alcanzará su antigua nacionalidad por el redentor empuje de la democracia universal, y dejando por imposibles a China, Turquía y Marruecos,

23 Macías Picavea, Ricardo: El problema nacional, Madrid, Fundación Banco Exterior, 1992, p. 34. (1 ${ }^{\mathrm{a}}$ ed. 1899).

24 Fité, Vital: Las Desdichas de la Patria, Madrid, Fundación Banco Exterior, 1989 (primera edición 1899).

25 Ibid.

26 Archilés, Ferran: "Piel moruna, piel imperial. Imperialismo, nación y género en la España de la Restauración (c. 1880-c. 1909)," en Género, sexo y nación: representaciones y prácticas politicas en España (siglos XIX-XX). Mélanges de la Casa de Velázquez, 42 (2, 2012), 37-54; Torres Delgado, Gemma: Masculinitat i colonizatzió a Espanya: arquetips masculins al discurs colonial sobre el Marroc (1880-1927), tesis doctoral, Universitat de Barcelona, 2015.

27 Fité, Vital: Las Desdichas de la Patria, p. 209.

28 Ibid., p. 203.

29 Ibid., p. 208. 
como excepción de la regla, ningún pueblo que ha experimentado tales desgracias ha dejado de aplicar con vigor y energía el eficaz remedio a sus males, logrando en poco tiempo recobrar las fuerzas y el prestigio perdido ${ }^{30}$.

Esta visión, a la vez que denota un "realismo" nacionalista a la hora de entender la política internacional, puede resultar sorprendente por su universalismo: en principio, ningún grupo racial, cultural o religioso (al menos de aquellos que demostraron su grandeza en el pasado) parece estar a priori excluido, aunque entre los ejemplos positivos de recuperación rápida Vital Fité cita sólo a países que podrían definirse como cristianos, incluida la ortodoxa Rusia ${ }^{31}$. Sin embargo, sólo menciona a dos imperios y un reino como excepciones de la regla, sin aludir, por ejemplo, a Japón, Persia o la India, tampoco a ningún país latinoamericano.

Para ser un pueblo viril, no bastaba con haber alcanzado gloria y prestigio en el pasado. Había que mantener o recuperar algunas de las cualidades que llevaron a los antepasados a la grandeza, pero a la vez hacía falta imbuirse de los principios de la civilización moderna y redefinir en conformidad con aquellas las virtudes tradicionales. En cuanto al concepto de la civilización moderna, el discurso regeneracionista tiene fuertes continuidades con la tradición del liberalismo decimonónico, aunque teñidas de un mayor pesimismo en cuanto a ese nuevo mundo que se percibe como inevitable, pero no siempre como deseable, sobre todo en comparación con las visiones idealizadas del pasado áureo ${ }^{32}$. Los valores ensalzados enlazaban con el imaginario progresista de mediados del XIX, hasta con los pilares del reformismo ilustrado. Se trataba de fomentar la riqueza del país mediante el comercio y la industria en vez de la conquista, se instaba a todos los españoles a imbuirse de espíritu práctico y trabajar mucho de forma que correspondiera a su posición social, se proponía mejorar y generalizar la educación en saberes útiles, a menudo de forma diferenciada según los distintos grupos sociales. Se repite el énfasis en la educación como vehículo para moralizar el pueblo, a la vez que hacerlo más productivo. La tecnología ocupaba un lugar destacado en lo que se consideraba la civilización moderna hasta convertirse para muchos en un símbolo de la virilidad de los pueblos. Los pueblos que construyeran máquinas, cuyo territorio fuera surcado por los caminos de hierro, que sometieran las fuerzas de la Naturaleza a las necesidades del Hombre extrayendo las riquezas del subsuelo u obteniendo energía mediante la regulación de los ríos, tenían todas las características de un pueblo viril:

\footnotetext{
Miradlo ya en sazón; pueblos viriles se nutren de su pródigo sustento:

los yermos torna mágicos pensiles, Ceres moderna, va sembrando á miles los prolíficos granos de fomento.
}

$30 \quad$ Ibid., p. 207.

31 Ibid., p. 208.

32 El concepto de civilización estaba sufriendo cambios importantes a nivel transnacional en aquella época. Frente al significado clásico surgido en el siglo XVIII de civilización como un fenómeno de perfeccionamiento universal, en la segunda mitad del XIX se fue extendiendo una visión alternativa de civilizaciones múltiples situadas en el espacio y tiempo ("civilización occidental", "civilización islámica", "civilización china"). Sobre los orígenes del concepto, véase el apartado "Civilisation: évolution d'un mot et d'un groupe d'idées" en Febvre, Lucien : Pour une histoire à part entière, S.E.V.P.E.N., Paris, 1962. 


\begin{abstract}
¿Oís? La hora sonó de la partida, ved cual se lanza con febril exceso; igloria a los genios que te dieron vida! iplaza, plaza, al caballo del progreso! ${ }^{33}$.
\end{abstract}

Teniendo en mente este ideal, el diagnóstico que hacían los regeneracionistas de la "actual España económica" no podía ser más desolador: "pobreza, carestía, escasas ganancias, ausencia de ahorro, torpeza y barbarie técnica; las riquezas naturales, inexplotadas; tendencia al monopolio y a la usura; huida, en fin, creciente de la población desde las profesiones libres productoras hacia el mandarinazgo y el burocratismo." ${ }^{34}$ No podemos sino reparar en que este análisis deprimente moviliza eficaz, aunque implícitamente, el imaginario de género particular de la época. Así como a las mujeres de las clases acomodadas se les incentivaba a representar el status social de la familia mediante la ostentación, al mismo tiempo se les criticaba por la incapacidad de ahorrar. Las profesiones les estaban vetadas, pero su ociosidad era un signo de su inferioridad. Al mismo tiempo se observa toda una serie de referencias a la hipomasculinidad, o la virilidad insuficiente, empezando por la incapacidad de explotar las riquezas naturales. Hasta podríamos añadir que, según esta lógica, los españoles habían entregado su Naturaleza a los extranjeros para que la explotaran, incapaces de hacerlo ellos mismos. La referencia a la usura evocaba la imagen de hombres moralmente torcidos que vivían de forma improductiva a costa de otros. La renuncia a la independencia era el signo clave de la falta de virilidad: el monopolio y el "burocratismo" denotaban la dependencia del Estado, una situación cuyo estigma quedó reforzado en el texto de Macías Picavea a través de referencias a la hipomasculinidad oriental, en concreto al "mandarinazgo". Por muy exagerada que puede parecer esta observación, no debemos olvidar que el mismo autor que criticó el empleo público a través de la referencia al Imperio chino, afirmó que el Mediterráneo y el Atlántico eran los "únicos mares de la civilización" 35 . Referencias a la hipomasculinidad de los chinos aparecen en la obra de otro regeneracionista, Lucas Mallada, que les caracteriza como embriagados con opio, es decir, hombres que viven en un sueño, que se niegan a asumir la realidad y por lo tanto renuncian al autocontrol y a ser dueños de sus destinos ${ }^{36}$. Por último, la torpeza y la barbarie técnica alejaba a España de las naciones civilizadas en una operación retórica que hacía referencia tanto a la feminidad como a la hipomasculinidad, ya que el discurso del progreso - configurado a nivel transnacional desde la Ilustración- atribuía a las mujeres, a los salvajes y a los pueblos decadentes la falta de ingenio e industria, es decir, de la capacidad técnica más allá de lo rutinario. No es casualidad que fuera en esta época cuando los saberes técnicos estuvieran siendo apropiados por los hombres de élite e integrados en el discurso de la masculinidad hegemónica, aunque de forma cautelosa, ya que durante siglos habían conllevado el peligro para el status social debido a su cercanía al trabajo manual ${ }^{37}$.

33 Palau, Melchor de, "Oda a la locomotora”, Revista de Obras Públicas, 1, Año XXXVII, Serie 4, Tomo VII, Madrid, 15 de enero de 1889, pp. 2-3.

34 Macías Picavea, Ricardo: El problema ..., p. 145.

35 Macías Picavea, Ricardo: El problema..., p. 32.

36 Mallada, Lucas: Los Males de la Patria, Madrid, Fundación Banco Exterior, 1990, p. 48. (primera edición 1890).

37 Martykánová, Darina: “La profession, la masculinité et le travail. La représentation sociale des ingénieurs en Espagne pendant la deuxième moitié du XIXe siècle”, en Derouet, Antoine, Paye, Simon y Frapier, Christelle: $L a$ 
El progreso de las ciencias y de la industria se veía como un proceso natural e imparable a nivel de la Humanidad: "El positivo adelanto y constante perfeccionamiento de la civilización actual en el orden científico", es decir, "la marcha progresiva" de "todas las ciencias" y de la industria "ensanchan de día en día...el círculo de los conocimientos humanos, poniendo al servicio de la actividad industrial y constructora poderosos inventos de todo género", afirmaba un alumno de la Escuela de Caminos a finales del siglo $\mathrm{XIX}^{38}$. Es cierto que los ingenieros entre los regeneracionistas solían tener una visión del progreso científico y tecnológico más optimista que algunos de los intelectuales licenciados en Derecho o con un perfil humanístico. En este sentido, los primeros representaron la continuidad con el discurso liberal del Sexenio democrático, frente al creciente pesimismo en cuanto a la relación entre el progreso material, por una parte, y el progreso moral, por otra, expresado por los últimos. Mientras no cabía duda de que participar en el progreso material era fundamental para situarse entre las naciones aventajadas, muchos intelectuales españoles de la época llegaron a experimentar esta convicción sin mucho entusiasmo, como una inevitabilidad. Es más, mostraron preocupación por los efectos corruptores de la tecnología y por su supuesta incompatibilidad con las virtudes tradicionales del carácter español ${ }^{39}$.

La amargura con la que muchos aceptaron la inevitabilidad del progreso material se combinaba con un sentimiento de angustia que podía tener efectos movilizadores o paralizantes según cómo se enmarcaba cada asunto. Si el progreso de la civilización se consideraba como una constante a nivel global, la participación de las naciones en él no estaba en absoluto garantizada y había que luchar por ella y demostrarla constantemente. Los pueblos débiles o decadentes podían autoexcluirse de este proceso, por "frivolidad", "superstición", falta de voluntad y de laboriosidad, y también, o, sobre todo, por el mal gobierno de unas élites corruptas, débiles y poco patriotas, a veces opuestas a la "clase pobre" y la "medianía", que fueron consideradas como depositarias de un "verdadero sentimiento de la Patria" más puro que el de la clase "elevada" enlazaban con unas nociones de virilidad con muchos siglos de vigencia, el énfasis en la independencia de los hombres como actores públicos frente al caciquismo y al clientelismo se inscribe más decisivamente en la tradición liberal, tanto española, como transnacional. Lo mismo se podría decir de que reafirmaran la división entre lo público y lo privado, ya que el principio de la independencia y la crítica de las relaciones clientelares en la política, centrales en el análisis de los regeneracionistas como Joaquín Costa o Lucas Mallada, no se aplicaron de la misma manera sistemática al mundo de las relaciones laborales ${ }^{41}$.

Al mismo tiempo, los regeneracionistas identificaron una serie de rasgos compartidos colectivamente que había que expurgar. Así Pablo Alzola y Minondo, ingeniero de caminos y político regional, mantenía que "...la decadencia de España se debió en

production de l'ingénieur. Contributions à l'histoire sociale d'une catégorie professionnelle, Paris, Classiques Garnier (previsto para 2017).

38 De Los Terreros, Ramón S., "El arte en la ingeniería", Revista de Obras Públicas, 17 (1897), p. 452.

39 Sobre el uso por Unamuno de esta frase, véase por ejemplo Juaristi, Jon: Miguel de Unamuno, Madrid, Taurus Fundación March, 2012. Sobre el anti-industrialismo de algunos intelectuales españoles en la época finisecular, véase Litvak, Lily, A Dream of Arcadia: Anti-Industrialism in Spanish Literature, 1895-1905, University of Texas Press, 1975.

40 Fité, Vital: Las Desdichas...

41 Costa, Joaquín: Oligarquía y caciquismo como forma actual de gobierno en España: urgencia y modo de cambiarla, Madrid, Imprenta de los Hijos de M. G. Hernández, 1902; Mallada, Lucas: Los Males..., p. 91. 
gran parte...al espíritu romántico que miraba con total menosprecio el desarrollo de los intereses materiales, que son precisamente el nervio de las naciones bien formadas, y después de los tremendos fracasos antiguos y modernos se impone un cambio completo de rumbo en la dirección de este país desdichado..."42. Otro ingeniero entre los regeneracionistas, Lucas Mallada, también reivindicaba la necesidad de imbuirse del espíritu práctico que hacía fuertes a otras razas y era particularmente necesario en la época actual. Atribuía a los españoles una tendencia soñadora, un excesivo idealismo encargado en la figura de Don Quijote ${ }^{43}$. Los ingenieros tendían a construir dicotomías jerárquicas entre el idealismo y el espíritu práctico y criticar abiertamente la tendencia hacia lo poético que atribuían a los españoles, una inclinación que percibían poco útil en los tiempos que corrían. Además de interpretarla en el marco del debate regeneracionista sobre la virilidad de las razas, tenemos que entender esta retórica como una operación discursiva para redefinir lo que significaba ser un hombre de élite y dotar de mayor prestigio tanto a los saberes técnicos como al hecho de trabajar, en un ambiente en el que el trabajo no era el rasgo definitorio de la masculinidad hegemónica, los hijos de las élites estudiaban Derecho y los intelectuales más escuchados y respetados solían ser los escritores ${ }^{44}$.

Según Alzola, "España necesita dos cosas esenciales si ha de reconstituirse: Celebrar los funerales de D. Quijote de la Mancha aventando sus cenizas y adoptar como lema de su regeneración el apotegma de que Es preciso ser fuertes persiguiendo este fin primordial en un largo período de orden, de paz, de recogimiento, de moralidad y de trabajo que acreciente el patrimonio nacional hasta alcanzar la riqueza y el saber, bases imprescindibles para la fortaleza de las naciones." ${ }^{45} \mathrm{El}$ personaje de Don Quijote aparece una y otra vez en el discurso regeneracionista, una figura ridícula a la vez que trágica, de la que los españoles debían de alejarse. Por mucha simpatía que pudiera profesar uno u otro autor por el caballero manchego, su pureza de intenciones y su espíritu de lucha, su incapacidad de enfrentarse a la realidad y de adaptarse a ella le condenaban a desaparecer en una época en la que reinaba el espíritu práctico. Todos eran conscientes de que dar pena no era la manera de ganarse el respeto en la escena internacional, imaginada cada vez menos en términos de hermandad de pueblos y cada vez más como un ruedo en el que se libraba la lucha por la supervivencia de las naciones.

Aunque las metáforas bélicas para expresar las visiones sobre la Humanidad en general, y sobre la política internacional en particular, estaban al orden del día, al mismo tiempo observamos cómo Alzola y otros regeneracionistas defendían la tranquilidad y el orden como el ambiente más beneficioso para el desarrollo material, denunciando el idealismo revolucionario y el intervencionismo de los militares. Asimismo, dentro del discurso positivista hacían hincapié en el dominio de la ciencia y en el racionalismo, enfatizando como objetivo la fuerza de la nación más que el bienestar del pueblo. Entre los males a eliminar del carácter nacional había algunos identificados como tradicionales, incluso provechosos en un contexto histórico radicalmente distinto, que sin embargo podían resultar dañinos en la época actual.

42 Alzola y Minondo, Pablo: Historia de las obras públicas en España, Madrid, 1994, p. 446 (primera edición 1899).

43 Mallada, Lucas: Los Males..., p. 46-48.

44 Martykánová, Darina: « La profession, la masculinité... »

45 Alzola y Minondo, Pablo: Historia de las obras..., p. 449. 
Mientras que las referencias expresas a la hidalguía española solían hacerse en un contexto positivo, hubo en el discurso regeneracionista una crítica a lo que se percibía como residuo del pasado inapropiado en una nueva era: el desprecio al mundo material, a las prácticas capitalistas y al trabajo, el amor por lo inútil y un idealismo excesivo, hasta fanático que podía llevar a perturbaciones indeseables y a revoluciones mal encauzadas. Como hemos observado, para Alzola estas características tenían su encarnación par excellence en la figura de Don Quijote, al que no bastaba con enterrar, sino que había que aventar sus cenizas. Insertado en el contexto de la época contemporánea, Don Quijote aparece como una figura a la vez hipo- e hipermasculina, incapaz de situarse en la justa medida. Por una parte se pone un énfasis negativo sobre su ensoñación, su desconexión de la realidad y, por tanto, su incapacidad de actuar eficazmente sobre ella. Por otra parte, se le muestra como un idealista excesivo, perturbado y perturbador; su fe, valor y honor plasmándose en un fanatismo violento a la vez que inútil. Oponiéndose a lo que entendían como arrebatos revolucionarios, los regeneracionistas tendían a percibirse como hombres de orden que actuaron movidos por el deber de hacer oír su "protesta viril" contra las desdichas de la Patria, más que como guerreros dispuestos a usar la violencia para imponer su visión del mundo ${ }^{46}$.

El deseo del orden no estaba reñido con los deseos del cambio; es más, la pasividad de los españoles frente a los "desbarajustes administrativos" y la "inmoralidad pública" se entendían como un síntoma de la falta de virilidad de la nación, que apáticamente dejaba hacer a los gobernantes corruptos y a los que buscaban sólo su enriquecimiento personal, en vez de protestar por los "injustos atropellos y (...) los más repugnantes contrasentidos" ${ }^{47}$. En este sentido, los regeneracionistas sí proyectaron sus deseos de regeneración en toda la nación, más allá de las élites. Entonces: ¿qué se esperaba del pueblo español? Por una parte, los regeneracionistas tendían a compartir una visión muy pesimista de su estado actual. Algunos entendían como natural que el pueblo fuera rudo e ignorante, ya que tal visión encajaba en su visión clasista de la sociedad. El problema, según ellos, estaba en que el pueblo español a la vez fuese débil y viciado. Es cierto que hubo regeneracionistas que interiorizaran la noción muy extendida en los nacionalismos finiseculares (entre otros el alemán, el vasco o el checo, e incluso el estadounidense, en su versión particular del "Oeste Salvaje") de que era en las aldeas donde se deberían buscar las profundas virtudes nacionales y una virilidad que no fuera debilitada por las comodidades y corrupciones de la vida urbana. Dentro de esta lógica buscaban las explicaciones de la situación en el estado generalizado de la sociedad española y, sobre todo, en que las élites españolas, en vez de cumplir su deber de liderazgo, contribuían con sus malas prácticas gubernamentales a la corrupción de los labradores: "Concediendo, como es fuerza conceder, que la clase labradora es en todas partes del mundo la más honrada y virtuosa, por el desquiciamiento general de la sociedad española, también por los pueblos entraron hace muchos años por la senda de perdición de abusos inmorales y rudos atropellos"48. También la extensión del caciquismo era el signo de la falta de fuerza de la nación, de la debilidad de un pueblo habituado a adoptar actitudes servi-

\footnotetext{
46 Fité, Vital: Las Desdichas..., p. 206.

47 Mallada, Lucas: Los Males..., p. 98.

48 Ibid., p. 179.
} 
les durante los siglos del Antiguo Régimen ${ }^{49}$. Hasta los hombres bienintencionados podían acabar engullidos por el sistema, cooptados por las élites corrompidas: "La masa general de la nación seguía acostumbrada a doblar las rodillas delante de los caciques, ya fueran éstos descendientes de la antigua nobleza, o sucesores de acaudalados burgueses, o simples revolucionarios que del fondo de una barricada o de los rincones de los cuarteles pasaban victoriosos a mezclarse amigablemente con los más encopetados cortesanos" $" 50$.

La nación se había vuelto cobarde debido a la combinación del servilismo que fomentaba el miedo y la dependencia, por una parte, y el deseo de comodidad y de bienestar material, incentivado por el capitalismo industrial, por otra parte.

Desdichada condición de todo país decadente o imposibilitado en mucho tiempo de regenerarse es la falta de virilidad, o sea la cobardía, que lleva aparejada consigo la maledicencia, gracias a la cual, ya que falte valor para formular acusaciones concretas y para expulsar del trato común de las personas honradas a los bribones...Nadie impide, sin embargo, que, como mujerzuelas chismosas y viejezuelas entrometidas, nos reunamos en los paseos y plazas, en los cafés y casinos, y unos y otros nos vayamos enterando de la astucia de los advenedizos, confundidos ayer entre la más perversa canalla, convertidos hoy en encopetados señores, y de cómo se crearon las fortunas improvisadas en nuestro tiempo....Todo se fía a la recomendación y a la intriga, nada a la justicia y la razón... ${ }^{51}$.

El diagnóstico ponía énfasis en el personalismo y la arbitrariedad del poder, frente a la fuerza de los principios, y en cómo esto doblegaba a los hombres, obligándoles utilizar las armas de los débiles: el chismorreo y la intriga. En las concepciones de género vigentes, eso suponía un afeminamiento entendido como falta de virilidad. Estas críticas se expresaban en términos de género de forma explícita, haciendo entrever que la visión que planteaba la feminidad como una carencia de virilidad seguía siendo muy potente, y si bien se fue transformando, no fue plenamente reemplazada por la visión de los sexos opuestos y complementarios, lo que confirma la tesis de Nerea Aresti sobre la pervivencia de la visión jerárquica hasta los años 1920, cuando culminó un proceso de largo alcance temporal en el que se radicalizó la idea de la complementariedad de sexos opuestos ${ }^{52}$.

Remarquemos que, aunque se escribiera sobre el estado de los labradores, el debate regeneracionista volvía muy rápido a la responsabilidad de las élites. La preocupación constante de los regeneracionistas es la falta de virtud y la deslegitimación de las élites. Su falta de altura para este deber rozaba lo criminal. Lucas Mallada llegó hasta asemejar implícitamente a los hombres públicos a las prostitutas, haciendo juego con la diferencia en el significado de las expresiones de "hombre público" y "mujer pública"53. Por su parte, Juan Vázquez de Mella definió a las élites gobernantes

49 Ibid., p. 185 y 188.

50 Ibid., p. 185-186.

51 Ibid., p. 175-176.

52 Aresti, Nerea: Masculinidades en tela de juicio: hombres y género en el primer tercio del siglo XX, Cátedra, 2010; Médicos, donjuanes y mujeres modernas. Los ideales de feminidad y masculinidad en el primer tercio del siglo XX, Bilbao/Zarautz, Universidad del País Vasco, 2002 y "El ángel del hogar y sus demonios. Ciencia, religión y género en la España del siglo XIX”, Revista de Historia Contemporánea, n²1, 2000, pp. 363-394.

53 Mallada, Lucas: Los Males..., p. 179. 
como "un rebaño de golfos y presidiarios, verdadera colonia penitenciaria", acusándoles de haber reducido la sociedad española "a la manada de siervos y mendigos" 54 . No era el Antiguo Régimen con sus "siervos y vasallos" el que cargase con todas las culpas del estado de las cosas. Los regeneracionistas deploraron que el deseo de "competir en lujo y en boato," el decir, el consumismo, sustituyera la austeridad que, según la visión idealizada del pasado, había caracterizado la vida de los caballeros en los tiempos pasados.

En su crítica acérrima de la "oligarquía", estos hombres argumentaban que el mal venía de arriba abajo, pero su insistencia en este reparto de responsabilidades denotaba también cierta falta de expectativas en cuanto a la capacidad del pueblo para autogobernarse. La llamada clase elevada se construyó colectivamente como hipomasculina: ociosa, corrupta, decadente, llevada por pasiones egoístas, dada a la retórica vacía, inclinada a preferir los intereses familiares frente a los de la Patria. Por otra parte, la crítica era demoledora precisamente porque eran estos grupos que se entendían en términos termodinámicos como las fuerzas vivas y de los que se esperaba el liderazgo necesario ${ }^{55}$. La crítica de las élites era más dura precisamente porque eran ellas las que, según los regeneracionistas, debían gobernar y de ellas se esperaba la regeneración. Si las élites destacaban por su corrupción, debilidad y dependencia de los favores de otros, no podían sino ostentar una notable falta de virilidad, lo que se trasladaba en la falta de capacidad para ejercer el poder de forma legítima. Algunos personajes destacados como Joaquín Costa plantearon una regeneración movilizadora en términos de populismo agrario ${ }^{56}$ para otros como Giner de los Ríos la regeneración suponía dotar el pueblo de herramientas intelectuales para liberarse y autogobernarse, pero incluso para ellos un pueblo activo constituía un horizonte de expectativas, para apropiarse del término de Koselleck, no una necesidad del presente, y para llegar allí hacía falta liderazgo adecuado por parte de hombres fuertes, dotados de habilidades especiales y de una virtud que les hacía destacar. Los regeneracionistas deseaban con todas sus fuerzas una autoridad a la vez fuerte y legítima. Su propósito no era el de destruir la autoridad de las élites, sino ampliarlas, redefinirlas y dotarlas de una nueva legitimidad. En este sentido, el regeneracionismo contenía rasgos mesocráticos, y la "mediana" aparecía a veces como el depósito de la esperanza por combinar el patriotismo y la capacidad ${ }^{57}$. Tampoco se trataba de cuestionar las jerarquías per se, sino reinstaurarlas de una forma que el mundo resultara ordenado y previsible en las nuevas circunstancias.

En este contexto discursivo cargado de nociones de género, hasta criticar la "flojedad" de relaciones comerciales con Cuba y Puerto Rico movilizaba un imaginario de género que ponía en evidencia la insuficiencia de los peninsulares a la hora de

54 Juan Vázquez de Mella en El correo español, 10 marzo 1898, citado en Armero, Álvaro: Fragmentos del 98. Prensa e Información en el año del desastre, Madrid, Comunidad de Madrid. 1998, p. 63.

55 El uso del lenguaje de la termodinámica fue muy extendido en las obras de la época sobre la política y la sociedad, y fue así a nivel transnacional. Martykánová, Darina: "Palabras de la ciencia útil: los pilares conceptuales del discurso corporativo de los ingenieros de Estado", en Pérez Ledesma, Manuel (ed.): Lenguajes de la Modernidad en la Península ibérica, UAM, Madrid, 2012, pp. 389-430.

56 Ortí, Alfonso: "Para analizar el populismo: movimiento, ideología y discursos populistas. El caso de Joaquín Costa: populismo, agrario y populismo españolista imaginario”, Historia Social, 2, 1988, 75-98.

57 Sobre la noción de las "clases medias" en el discurso liberal decimonónico, véase Sánchez León, Pablo: "La pesadilla mesocrática: ciudadanía y clases medias en el orden liberal histórico español”, en Manuel Pérez Ledesma (ed.): De súbditos a ciudadanos. Una historia de la ciudadanía en España, Madrid, Centro de Estudios Políticos y Constitucionales, 2007, pp. 135-164. 
seducir, someter y explotar adecuadamente a las díscolas colonias de Ultramar, dejando campo libre a los ingleses y estadounidenses que las estaban rondando ${ }^{58}$. La preocupación por la fuerza económica se combinaba por el deseo de reforzar el control territorial, a la vez vehículo del fomento de la riqueza y signo de dominio viril de la nación. En la Europa finisecular, la pérdida territorial se llegó a experimentar como amputación de órganos vitales, una experiencia traumática que marcaba profundamente las conciencias no solamente de las élites gobernantes, sino también de las capas cada vez más amplias de la población (que, además sufrían a menudo las mutilaciones en sus propios cuerpos, teniendo en cuenta que los conflictos bélicos en los que redibujaba el mapa del mundo implicaban cada vez mayor parte de la población masculina $)^{59}$. Éste había sido el caso de la derrota de Francia en la guerra con Prusia en 1871, éste fue el caso del Desastre español de 1898 y lo iba a ser el caso de las derrotas otomanas en las guerras balcánicas de 1912-1913. Las pérdidas de lo que había sido considerado como el territorio nacional provocaron profundas crisis de liderazgo, hasta impulsar en ocasiones cambios de régimen. Es más, dentro de un ambiente caracterizado por la movilización creciente de la población, estas pérdidas pudieron suponer una profunda crisis de identidad nacional, articulada en términos de género. Los conflictos bélicos se expresaron en el lenguaje de honor y de humillación, de virilidades en competencia por la dominación ${ }^{60}$. En las representaciones visuales, el territorio (España, Cuba, etc.) solía aparecer encarnado en la figura de una mujer, la madre patria protegida por sus hijos o la joven desamparada o abusada en busca de un protector benévolo ${ }^{61}$. La percepción del poderío militar como signo de la proeza de los hombres españoles estaba relacionada con la creciente identificación de la población con la nación. De esta forma, las derrotas y las pérdidas territoriales se vivían como castración, y la incapacidad de recuperar los territorios o emprender expansión colonial como Francia o Gran Bretaña, como síntoma de la impotencia nacional y por ende, de los hombres españoles. En España, la pérdida finisecular de las colonias supuso la exacerbación de las angustias sobre la coherencia territorial en la Península Ibérica, sobre todo en lo que concernía a Cataluña. Este tema está tratado a fondo en otro artículo de este dossier, el de Helena Miguélez-Carballeira. Baste decir que el asunto se articuló mediante discursos cargados de nociones de género, que con gran frecuencia empleaban metáforas como la de una relación amorosa o la del matrimonio ${ }^{62}$.

Si bien es cierto que las derrotas finiseculares se vivieron como un problema que concernía a toda la nación, los regeneracionistas expresaron sus expectativas en

58 Mallada, Lucas: Los Males..., p. 163.

59 Para el caso del impacto de la lucha por la independencia cubana y, más adelante, de la pérdida de Cuba, no solamente el nacionalismo español, sino también en el despertar de los otros nacionalismos peninsulares, véase Ucelay da Cal, Enrique: "Cuba y el despertar de los nacionalismos peninsulares", en Studia Historica. Historia contemporánea, 15, 151-192.

60 Aunque varios antropólogos, como también algunos investigadores hispanistas que trabajan en el área de "Cultural Studies," definen la sociedad española como una sociedad en honor y vergüenza, junto con otras sociedades mediterráneas, este tipo de imaginario estaba generalizado a la hora de tratar de derrotas y victorias militares también en otras partes de Europa. De hecho, últimamente han surgido estudios interesantes que cuestionan la supuesta "obsesión con el honor" como un rasgo definitorio de los españoles, incluso para la época clásica del "Siglo de Oro". Véase: Taylor, Scott K.: Honor and Violence in Golden Age Spain, Yale University Press, New Haven/Londres, 2008.

61 Algunas observaciones interesantes en este sentido en Aresti, Nerea: "A la nación por la masculinidad...".

62 Miguélez-Carballeira, Helena: "The Imperial Within: Discourses of Masculinity and Empire in the Twentiethcentury Spanish and Catalan National Imagination”, en este dossier de Cuadernos de Historia Contemporánea. 
cuanto al pueblo de forma bastante más ambigua que sus preocupaciones por la calidad del liderazgo. Algunos parecen depositar muchas esperanzas en una educación adecuada que pudiera activar el potencial del pueblo y crear una masa de ciudadanos movilizados para la causa de España y vigilantes frente a la corrupción de los gobernantes, que al mismo tiempo aceptaran sin rebelión o resistencia pasiva el liderazgo de una élite ampliada hacia las clases medias y sobre todo, meritocrática. Otros ven inevitable para la regeneración el gobierno de un hombre fuerte, lo que podríamos llamar la dictadura tutelar (Picavea) ${ }^{63}$. La manera en la que algunos regeneracionistas representaron y criticaron a los militares, apoyaría esta interpretación. Sobre todo después del Desastre, los militares eran objeto de una fuerte crítica en cuya articulación se observan elementos de género. Por una parte, se les atribuían rasgos hipermasculinos, a menudo entendidos como tradicionalmente presentes en cierto tipo del hombre español. Estos serían, por ejemplo, la impulsividad, el sentido exacerbado del honor, la intransigencia y la violencia, que adquieren tintes claramente negativos al ser opuestos discursivamente a la prudencia, a la represión de sentimientos individuales a favor del bien común y a la negociación como forma civilizada de resolver las diferencias, que al mismo tiempo es más provechosa y útil y por eso resulta más inteligente que la intransigencia y la violencia. En un juego complejo de significados y de imaginarios movilizados, estas y otras características atribuidas a los militares pueden construirse a veces también como hipomasculinas: el militar aparece como un ser poco racional e inestable, arrastrado por pasiones exageradas, incapaz de controlar sus impulsos, todos estos razones alegadas a lo largo del siglo XIX para justificar la exclusión de las mujeres de la vida política ${ }^{64}$.

Es cierto que esta crítica a los militares no necesariamente estigmatizaba a cada hombre salido del ejército, sobre todo si este fuera capaz de ejercer de "dictador regeneracionista" sin que dependiera del apoyo constante del ejército o se apoyara sistemáticamente en él. La crítica de la oligarquía corrupta adquiere en algunas obras regeneracionistas fuertes tintes de antiparlamentarismo (Picavea), y el hombre fuerte, el "cirujano de hierro" de Costa, efectivamente aparece como una solución, un ejemplo de virilidad en acción, frente al Parlamento como símbolo de la desunión, de la palabrería y de la incapacidad a la hora de tomar decisiones. El imaginario movilizado en esta crítica es el de una casa en desorden, y la acción del que impusiera orden, se entendería no solamente como provechosa, sino también como natural, comparable con el deber de un buen padre de familia.

El discurso regeneracionista muestra una importante pluralidad, además de toda una serie de tensiones internas y de ambigüedades, que, por otra parte, lo hacían flexible y adaptable. El énfasis en la fuerza y en la fortaleza se combina con la identificación de la conquista y de la violencia con los modos de hacer particulares del pasado, superados e inapropiados en el marco de la civilización moderna. La alabanza implícita o explícita de la prudencia, del pragmatismo y de la búsqueda legítima de

63 Algunos historiadores han visto en el regeneracionismo una especie de proto-fascismo, mientras otros como Javier Tusell mantienen que, a pesar de que algunos entendían como necesaria la figura de un dictador temporal y el regeneracionismo se convirtió en el arsenal discursivo legitimador de la dictadura de Miguel Primo de Rivera, muchos regeneracionistas operaron más bien dentro del paradigma liberal. Tusell, Javier: "El regeneracionismo de Vital Fité”, en Fité, Vital: Las Desdichas..., pp. 7-13.

64 Mallada presenta una lista de los males que afectan la agricultura en España, citando en el punto 9 el militarismo. Mallada, Lucas: Los Males..., p. 91. Una crítica del militarismo como históricamente superado y generalmente dañino en Fité, Vital: Las Desdichas..., p. 23 y otras. 
los intereses materiales no impedía centrar la crítica en "el convencionalismo", "el egoísmo" y "la indiferencia" generalizados, sobre todo entre las "clases elevadas." El convencionalismo se refiere a que uno actúe según le convenga, de forma egoísta. Todos estos "males" se contraponen al sentimiento patriótico, que está en el mismo centro del discurso regeneracionista, identificado como la fuerza motora del cambio, como el remedio básico para todos los males. Al mismo tiempo que ensalzan esta identidad colectiva, la manera de entender la acción tiende a ser voluntarista: "el querer es poder", aparentemente exclamaban algunos en el marco de los debates sobre la regeneración ${ }^{65}$. Cada uno por su cuenta, y según corresponde a su posición social, los españoles deben esforzarse, motivados por el sentimiento patriótico, para lograr la vuelta de España entre las potencias de primer orden, mediante una fusión eficaz de las virtudes de la civilización moderna y el espíritu históricamente enraizado de la raza adaptado a los nuevos tiempos. José Echegaray -ingeniero, político y dramaturgo- no puede dejarlo más claro: "Que cada español, en su esfera propia, grande, o pequeña, o modesta, haga lo que pueda, y esto basta." ${ }^{66}$ Es decir, para ser un pueblo viril, todos los hombres deben comportarse de forma que honre a un hombre. En este sentido, el discurso regeneracionista español aparece como moralizante, $\mathrm{y}$, en cierto modo, individualista ${ }^{67}$.

En un análisis que combina marxismo con lecturas freudianas, Alfonso Ortí describe esta dinámica en términos de las tensiones particulares de las sociedades capitalistas semiperiféricas como una "reducción de la política a una esfera o conjunto de simples comportamientos individuales, [lo que] convierte a la concepción política regeneracionista en un moralismo político, que considera la acción política positiva como una cuestión ética de honradez y buena voluntad personal, de energía y determinación morales y de esfuerzo por perfección". Al mismo tiempo llama la atención a que este moralismo político es indisociable de un pesimismo cultural y antropológico que "tiende a condensarse en un masoquismo moral", según el que las "prácticas reales de todas las capas de ciudadanos aparecen (...) como irremediablemente inmorales y corrompidos" 68 .

No es de sorprender que una parte importante de las propuestas concretas de los regeneracionistas se centrase en reformar las altas esferas del gobierno y las instituciones jerárquicas como el Ejército y la Marina, además de proponer actuaciones desde el Estado supervisadas por los cuerpos de elite, como puede ser por ejemplo la construcción masiva de obras públicas, siendo estas, además, metáforas potentes del dominio del Hombre sobre la Naturaleza. Las propuestas orientadas hacia la población en general solían plantearse como acciones definidas y llevadas a cabo desde

65 Así lo afirma Fité, Vital: Las Desdichas..., p. 208.

66 José Echegaray en el Discurso leído por el Excmo. Señor D. José Echegaray el día 10 de noviembre de 1898 en el Ateneo científico, literario y artístico de Madrid con motivo de la apertura de sus cátedras, Madrid, Sucesores de Rivadeneyra, 1898

67 Es cierto que los regeneracionistas también formularon propuestas dirigidas a la población en general. Estas fueron articuladas en términos de reformismo higienista o en términos pedagógicos de educación y cultivación. Autores como Mallada estaban preocupados por la falta de "energía vital" de la raza latina frente a los eslavos y anglosajones y también por los rastros de debilidad en el físico de los españoles. Mallada, Lucas: Los Males ..., p. 46. A la hora de proponer remedios, las sugerencias entrarían en el marco del higienismo o de lo que proponían algunos autodenominados eugenistas latinos, es decir, el énfasis en la educación, incluida la de las mujeres destinadas a ser madres, en la mejora de higiene y en la lucha contra la pobreza no para resolver la llamada "cuestión social", sino para mejorar las características físicas de la raza mejorando las condiciones de vida de las clases desfavorecidas.

68 Ortí, "Regeneracionismo...", p. 89-90. 
arriba hacia las masas emasculadas, bajo la dirección de unas élites redefinidas y ampliadas, capaces de ejercer el liderazgo gracias de haber reconstruido su virilidad, y que no sufrían los problemas que su acción pretendía resolver. En este sentido, el yugo del caballero español consistía en asumir la responsabilidad por que el pueblo español recuperase su virilidad, indispensable para sobrevivir y triunfar en la competencia exacerbada entre las naciones.

\section{El regeneracionismo y la masculinidad hegemónica de la época}

Podríamos asimismo preguntarnos qué supuso la expansión del discurso de la regeneración en España para el discurso de la masculinidad, para la construcción de lo que es un hombre. Si bien quiero desarrollar este asunto en el futuro en una investigación independiente, quisiera apuntar algunas hipótesis basadas en la investigación parcial que he llevado a cabo, combinada con las pistas que han proporcionado otras investigadoras como Nerea Aresti o Victoria Blacik ${ }^{69}$. Puede resultar llamativo que, siendo la necesidad de cambio el punto clave del discurso regeneracionista, las nociones de la masculinidad que éste movilizaba y promovía estaban, en realidad, profundamente enraizadas en el imaginario social no sólo liberal sino también de longue-durée. Los regeneracionistas hablaban de enterrar a Don Quijote y aventar sus cenizas, pero su discurso y su autorrepresentación fueron imbuidos de nociones clásicas de honor, valor y sobriedad, además de ensalzar la actividad pública, el trabajo duro, el pragmatismo y la utilidad. En general, la imagen del hombre del futuro no mostraba rasgos muy novedosos si lo comparamos con mediados del siglo XIX, y tenía un matiz elitista. Así por ejemplo, las referencias al trabajo estaban bastante alejadas del trabajo manual, que - por mucha utilidad que se le reconociese - se consideraba como algo "pequeño", propio de gente "humilde" y por lo tanto, empequeñecedor, además de embrutecedor en el caso de trabajo físicamente muy exigente como labranza o minería ${ }^{70}$. Es más, incluso el empleo asalariado, sobre todo en el sector privado, se construía como algo problemático para la masculinidad hegemónica, poniendo en duda la independencia del hombre que lo desempeñaba y construyéndole como débil y temeroso de perder su puesto ${ }^{71}$. El imaginario regeneracionista más bien conectaba con la noción del "hombre público", propietario residente en la ciudad que empleaba su tiempo en negocios, política, letras y ciencias, y que había caracterizado la masculinidad hegemónica española desde hacía décadas ${ }^{72}$. Las élites profesionales como los médicos y los ingenieros habían intentado legitimar socialmente el empleo asalariado cualificado como digno de un "caballero" y esencial para el "progreso de la civilización" y el regeneracionismo reforzó sus esfuerzos al vincular las nociones de la utilidad pública y del bien común a las obras públicas y a las medidas higienistas. Se empezaba a hacer notar también la presión discursiva

69 Aresti, Nerea: Masculinidades en tela de juicio...; Blacik, Victoria: "Murder, Médicos Titulares, and Modernization in Restoration Spain: The Campaigns in Support of Dr. Alfredo Alegre, 1915-1924", ponencia en el 126 Conferencia Anual de la American Historical Association, Chicago, 5-8 enero 2012. Agradezco a la autora el haberme proporcionado el texto de su ponencia.

70 Martykánová, Darina: «La profession, la masculinité...».

71 Ibid.

72 Sierra, María: "Política, romanticismo y masculinidad: Tassara (1817-1875)", Historia y Política. Ideas, Procesos y Movimientos Sociales, 27, 2012, pp. 203-226. 
desde el movimiento obrero y el socialismo para situar el trabajo en el centro de la identidad masculina ${ }^{73}$. No obstante, el trabajo, lejos de convertirse en uno de los pilares de la masculinidad hegemónica, seguía resultando socialmente comprometedor, a diferencia de ser propietario, rentista o terrateniente sin otra ocupación. Lejos quedaban todavía los tiempos cuando todos los hombres buscarían presentarse como "los que trabajan", por ejemplo a través de la figura del "hombre de negocios" o "emprendedor". En general, los regeneracionistas contribuyeron de forma muy reducida a tensar las fronteras de la masculinidad hegemónica en la España de finales del siglo XIX y principios del $\mathrm{XX}^{74}$.

\section{Conclusiones}

El regeneracionismo español fue producto de la identificación de una parte de los hombres públicos españoles con la razón del Estado y la plasmación de su angustia por la pérdida de relevancia geopolítica que sufría España. Al vincular la fuerza del país con la virilidad de los españoles en general, y de sus élites en particular, las desavenencias militares y políticas se vivían con agudo dolor, como una emasculación. Al mismo tiempo, el regeneracionismo español conectaba con el discurso de decadencia y regeneración que tenía claras dimensiones transnacionales, lo que puede resultar algo irónico, ya que se basaba en una visión del mundo que insistía en la competición feroz entre las naciones. El concepto universalista del progreso hacía comparable a todas las entidades (imperios, países, naciones, civilizaciones) del mundo, exacerbando la competición, mientras los nacionalismos facilitaban la identificación entre la nación y cada uno de sus miembros, para bien y para mal. En este contexto, las nociones de modernidad y de tradición, de civilización y barbarie, de lo "nuestro" y lo "extranjero", fueron moldeadas mediante las nociones de género, de una forma compleja y fluida, que abría un amplio espacio de maniobra. De esta forma, las prácticas y los valores identificados como modernos podían ser interiorizados de forma selectiva, mientras que los supuestos "rasgos esenciales de la nación o raza" pudieron preservarse o ser redefinidos ${ }^{75}$. Por otra parte, si bien es cierto que el discurso regeneracionista planteó el problema nacional como un problema de virilidad y buscó soluciones a este mal en la recuperación de la hombría a través de la regeneración moral, no contribuyó en demasía a redefinir las nociones vigentes de la masculinidad hegemónica en España.

73 De Felipe Redondo, Jesús: "El concepto moderno-liberal de trabajador y su constitución como identidad histórica (1840-1870)", en Pérez Ledesma, Manuel (ed.): Lenguajes de la Modernidad..., pp. 353-388; y "Sexualidad y movimiento obrero español. La transformación de las identidades masculinas frente a la cuestión del trabajo femenino, 1830-1870", ponencia en el taller Masculinidad, Nación y civilización en España (18301930), organizado en el marco del proyecto Marie Curie CIG TECHDEM el 15 de enero de 2016 en Madrid.

74 Lo que confirma las tesis ya citadas de Aresti, Nerea: Masculinidades en tela de juicio...

75 Malecková, Jitka: Úrodná půda... 